\title{
LADY HAMILTON: FICÇÃO E CONTROLE SOCIAL
}

Fábio Figueiredo Camargo (UFU)

Resumo: Em Homossexualismo masculino, publicado em 1953, Jorge Jaime apresenta um diário denominado Lady Hamilton. O livro é uma tese apresentada em 1947 para a cadeira de Medicina Legal na Faculdade de Direito da Universidade do Brasil. Lady Hamilton, que o autor afirma não ser escrito por ele, é o diário de um personagem homoerótico. Nessa ficção de ordem médico-legal se estabelece o modo como um sujeito homoerótico não pode ou não deve se comportar, tomando a literatura como espelho da sociedade. A partir de questões como "autobiografia", de Philipe Lejeune e de "escritas de si" de Michel Foucault, pretende-se analisar Lady Hamilton em seu jogo de afirmar-se enquanto ficção e ser produzido para o controle social do homossexualismo. Nesse jogo, o literário parece escapar à mera conformação a uma ideologia heteronormativa.

Palavras-chave: Literatura brasileira, homoerotismo, gênero, controle social.

Abstract: At Homossexualismo masculino, published in 1953, Jorge Jaime presented a daily called Lady Hamilton. The book is a thesis presented in 1947 to the Chair of Forensic Medicine in Faculty of Law at the University of Brazil. Lady Hamilton, that the author claims not to be written by him, is the diary of a gay character. In this fictional medical-legal order is stablished how can not or should not a homosexual behave, taking the literature as a mirror of society. From questions such as "autobiography" of Philippe Lejeune and "self-writen" by Michel Foucault, we intend to analyze Lady Hamilton in his game to assert itself and to be produced for the social control of homosexuality. In this game, the literature seems to escape mere conformity to a heteronormative ideology.

Keywords: Brazilian literature, homoeroticism, gender, social control.

A novela Lady Hamilton, de Jorge Jaime, é publicada em 1953 em seu livro Homossexualismo masculino, como complemento à sua tese apresentada em 1947 para a cadeira 
de Medicina Legal na Faculdade de Direito da Universidade do Brasil. De acordo com Carlos Figari, o romance "repetia todos os antigos axiomas do discurso médico-legal: degeneração, anomalia endócrina, criminalidade e reclusão em instituições especializadas [...]" (FIGARI, 2007, p. 370).

James Green, ao historiar a questão do homossexualismo no Brasil, faz uma análise sobre a capa do livro de Jaime, quando de seu lançamento em 1953. De acordo com Green,

Fica-se logo impressionado com o projeto da capa do livro, que lembra a arte européia e norte-americana dos anos 50 e 60 . Um jovem loiro e belo domina o espaço, lançando um olhar longínquo, talvez inocente, ou quem sabe romântico. Um pouco acima dele, à esquerda, está um homem mais velho igualmente atraente, usando bigode. Sua expressão sugere proteção e afeto pelo jovem. A imagem não veicula a idéia de degeneração, doença ou perversão, e sim uma relação benéfica entre os dois homens. Como um recurso de marketing, a capa sem dúvida deve ter atraído muitos homossexuais brasileiros, que provavelmente julgaram que ali encontrariam um tratamento positivo do assunto. Lamentavelmente, devem ter ficado desapontados. (GREEN, 2000, p. 282)

Green dedica algumas páginas para analisar o livro de Jaime e ainda trata da novela Lady Hamilton como uma 
história "excessivamente melodramática e fantasiosa"; cita o texto de D. Franco que enxerga a novela como algo ruim, afirmando que esta deveria ser lida como "gozação" (FRANCO, Apud GREEN, 2000, p. 287). Nota-se, portanto, na visão dos três pesquisadores que se debruçaram sobre Lady Hamilton, que este não é muito recomendado devido à sua carga preconceituosa para com o assunto. Green deixa claro que o livro de Jaime é propaganda enganosa e corrobora a ideia de D. Franco de que a novela contida em Homossexualismo masculino não deve ser levada a sério.

O livro teve uma segunda edição ainda em 1953, o que dá ideia de seu sucesso. $\mathrm{O}$ autor, na segunda edição, apresenta algumas "críticas", todas elogiosas, sobre o livro. Recorto alguns trechos de cartas enviadas ao autor publicadas na segunda edição relativas à novela em tela. Deve-se salientar mais uma jogada de marketing, além da capa chamativa, de Jorge Jaime: a autorreferencialidade e a autolouvação a partir de cartas assinadas por um outro que não o autor do livro, mas tornadas públicas por este. Uma dessas cartas é de Hernani de Irajá, que tece altos elogios a Homossexualismo masculino e afirma sobre Lady Hamilton:

parte semi-novelística, em que Jorge Jaime concatenou vários flagrantes de romances desses passionais, e que denominou "Lady Hamilton". É a parte mais desenvolvida 
do presente trabalho, e nelas se pode aquilatar dos dotes literários do jovem cientista patrício, "doublé" de escritor com apreciável técnica descritiva. (IRAJÁ, Apud JAIME, 1953, s/n)

Hernani de Irajá foi o sexólogo responsável por publicações de muito sucesso no Brasil entre os anos 1920 a 1960 sobre as questões sexuais, cujo livro Psicoses de amor, o qual tratava justamente da questão homossexual, estava, em 1931, na sua quarta edição. Para o mercado editorial brasileiro isso é ser best-seller. Note-se que a afirmação de Irajá indica que a novela é a parte mais desenvolvida de Homossexualismo masculino, o que poderia apontar para o fato de que a tese não o satisfazia inteiramente. Do mesmo modo, a afirmação de Irajá vai ao encontro de que há uma estratégia por parte de Jorge Jaime em concatenar "vários flagrantes desses passionais". Isso está de acordo com a apresentação produzida por Jaime ao final de Homossexualismo masculino.

Uma outra carta apresentada na segunda edição é a do jornalista e crítico musical Oberon, totalmente desconhecido, podendo ser um pseudônimo, que faz a seguinte afirmação sobre Lady Hamilton:

A história de "Lady Hamilton" sintetiza a história de milhões de rapazes espalhados pelo mundo, na mesma ânsia, na mesma luta. É uma tragédia permanente, sem 
princípio nem fim, porque quando surgem no palco da vida já a encontram latente, eloqüente, vivaz, exterminando tudo, destruindo molécula, por molécula, (sic) nervos por nervos, tudo e até finalmente a mais insignificante reserva moral. (OBERON Apud JAIME, 1953, s/n)

As afirmações apresentadas por Oberon são todas muito positivas e dão o tom do que deve ser a novela ou a seminovela de Jorge Jaime. Um texto utilizado como exemplo do que ocorre com "milhões de rapazes espalhados pelo mundo", isto é, um texto produzido para a pedagogia do sujeito dito anormal. Texto capaz de educar àqueles que por acaso pensam em sair do esquema que a sociedade espera deles. Embora os críticos citados no começo do livro de Jorge Jaime não sejam de todo recomendáveis, pois não são propriamente críticos literários, suas opiniões demonstram o que se veicula a partir de um texto como Lady Hamilton e dão mostras do pensamento da época de sua produção sobre o assunto. Espera-se, de acordo com a visão desses críticos, que, ao se depararem com os sofrimentos do personagem principal, os leitores não sejam capazes ou não pretendam levar uma vida tão desregrada que os levará fatalmente à morte.

Em conformidade com esse raciocínio, Jorge Jaime, em 
sua introdução a Homossexualismo masculino, informa a seus leitores:

São muitos, homens, só homens que se beijam uns aos outros, e se devoram, e se desgraçam. É uma legião imensa de viciados que se atira no lodo da prostituição e se afoga nos charcos de fezes. Eu os quis estudar, conhecer a mentalidade coletiva desses doentes tarados. [...] Perdoai-os; são doentes, não sabem o que fazem. (JAIME, 1953, s/n).

Pelo trecho anteriormente citado percebe-se de onde parte o discurso do autor. Para ele, os homossexuais são sujeitos degenerados que frequentam ambientes sórdidos conotados na expressão "lodo". Como não poderia deixar de ser, a expressão "charco de fezes" completa o restante do argumento, pois ao tomar os dejetos humanos e ligá-los à palavra charco, vocábulo que possui conotação negativa em nossa língua, ligado ao mais baixo, ao lodo e à lama, assume uma construção hiperbólica que demonstra o lugar que cabe aos sujeitos homoeroticamente orientados na cultura de seu tempo. Além disso, eles são chamados de "doentes tarados", carregam consigo a doença, pois na visão do autor os sujeitos homoeroticamente orientados não são responsáveis por sua orientação sexual, mas a contraem ou já nascem com ela. $A$ noção de que a tara é algo da ordem da hereditariedade é 
comum no pensamento da época; apresenta-se, portanto, quase como uma maldição, um estigma que esses sujeitos carregam. Aproveitando-se de todo um discurso médico, o autor apela ao final para o discurso religioso, ao repetir as palavras de Cristo no novo testamento. Esse é o modus operandi das ciências, no caso o direito e porque não dizer da medicina, na metade do século XX no Brasil. Os textos de James Green (2000), Carlos Figari (2007), João Silvério Trevisan (2002), dentre outros, dão conta de historicizar e analisar essas relações de controle social que essas ciências fizeram no país e que continuam a grassar ainda em pleno século XXI.

Voltando à novela Lady Hamilton, ao final de Homossexualismo masculino, antes de dar início ao texto, há um apêndice, no qual o autor apresenta uma série de cartas de homossexuais, para depois entrar com a seguinte informação:

Não querendo tornar-se (sic) prolixo, neste apêndice, a título de curiosidade, mostrarei, entretanto, uma novela escrita por um pederasta passivo, no quarto de um hospital onde veio a falecer. - O enredo - explicou-me ele - foi feito com passagens da vida dos principais homossexuais do Rio, no período da segunda grande guerra mundial. É a história de uma infinidade de uranistas, condensada numa só vida. Mas a alma, as dores são minhas. Se eu morrer, publique-a que fará um enorme sucesso, 
tenho a certeza. // Estive com ele até seus últimos momentos. Muitas páginas ditou-me, outras escreveu com seu próprio punho agonizante. Dir-se-ia, que antes de se despedir da vida, queria fazer um exame de consciência. Sofreu várias interferências cirúrgicas no reto. [...] // E este documento valioso mostro agora aos olhos da ciência, para que eles o analisem, horrorizem-se com tanto sofrimento e se compenetrem que é necessário fazer alguma coisa em prol dessa legião imensa de doentes, para que os olhos da ciência estudem-no e, conhecendo-o, esclareçam-se. (JAIME, 1953, p. $80-81$ ).

Esse trecho de tamanho considerável precisou ser citado para esclarecer mais uma estratégia literária de Jorge Jaime ao apresentar sua novela. Qual seja: a de apresentar um outro autor que não ele, Jorge Jaime, em um primeiro momento como modo de distanciamento entre ele, um cientista do Direito e o outro, o narrador, um homossexual passivo; a separação entre ficção e realidade. Note-se que o autor da novela é "um pederasta passivo" que faleceu "em um quarto de hospital". Jorge Jaime faz questão de apresentar a voz do autor da novela, ao utilizar o discurso direto, que indica como escreveu a mesma, utilizando-se da vida dos "principais homossexuais do Rio". O autor da novela deixa claro que sua alma está no texto e pede ao "Doutor" Jaime, 
autor da tese Homossexualismo masculino, para publicá-lo, com a indicação de que faria sucesso. A fala do "Doutor" Jaime aparece logo após o discurso direto do autor morto para informar aos leitores que o autor da novela morreu depois de muito sofrimento: "Sofreu várias interferências cirúrgicas no reto." Para completar a separação, a voz que representa a voz do "Doutor" afirma que este é um "valioso documento" que ele apresenta aos olhos da ciência, para que esta se compadeça dessa "legião imensa de doentes".

Diante de tamanho desejo de se separar do outro, dessa alteridade na qual não se reconhece, o "Doutor" bem intencionado, dá mostras de seu preconceito e do preconceito de sua época. Pretendo demonstrar como, mesmo querendo manter essa distância, que a literatura ultrapassa a barreira colocada pelo autor e toma conta do cenário, podendo produzir leituras diferenciadas daquelas que, a princípio, se desejou. Em que pese o desejo de se criar um texto que aponte os males do homossexualismo, gera-se um contradiscurso que pode também apontar para o quanto ele deve ser incentivado.

Jorge Jaime, antes de dar início à novela do "pederasta passivo" faz mais uma apresentação:

"Lady Hamilton" não é nenhuma obraprima da literatura. Se não tem valor 
como obra literária, vale apenas como um documento descritivo de todos os horrores degradantes que sofrem os milhões de pederastas que vivem sobre a face da terra. Que se horrorizem os gramáticos e os estilistas com tanto pronome mal colocado, mas que se esclareçam os legisladores quando fizerem leis para os doentes sexuais que conheçam as suas fraquezas involuntárias, que se compadeçam desses doentes infelizes - tal foi o meu propósito ao dar divulgação a este trabalho. (JAIME, 1953, p. 85).

$\mathrm{Na}$ apresentação, o mesmo discurso que anteriormente o autor já havia esboçado. O pedido de desculpas pelos erros de pronomes mal colocados faz parte do subterfúgio da negação de que o texto pertence a ele, "Doutor" em leis, que conhece o uso adequado da língua, ao contrário do autor da novela. Mantém-se os erros ortográficos e de pontuação para que não se perca a separação entre o texto do "pederasta passivo" e o do doutor em Direito. No mesmo tom, se o autor pede novas leis, sua lei internalizada apenas repete o discurso estigmatizante, ao considerar os sujeitos praticantes do homoerotismo "doentes sexuais" e "doentes infelizes". O propósito de divulgação do livro é claro, mudança das leis, mas não mudança das mentalidades. Intervenção e controle social através do discurso de um perverso. Os 
próprios leitores citados que apresentaram cartas ao autor dão mostras em seus discursos de que se deve alterar a legislação, mas conservam a denominação de "doentes" para os "pederastas".

A novela é um diário de um homossexual chamado Paulo, o qual narra sua vida a partir da adolescência em uma família de classe alta, passando por suas aventuras amorosas com vários parceiros, um casamento forçado com uma mulher até o momento da morte do personagem narrador do diário. A estratégia de Jorge Jaime está de acordo com a moda vigente ainda à época de apresentar a confissão de um perverso como instrumento pedagógico para o público. O diário dá uma ideia de pessoalidade e de verdade muito grande para a narrativa, sem contar que o pacto com o leitor é facilitado pela história que promete escândalos, sordidez, o que satisfaz e fascina as pessoas, leitoras da vida alheia. Deve-se salientar mais uma vez que a novela em forma de diário tem como base a "vida real" dos "principais homossexuais" do Rio de Janeiro. Sem contar com o fato de que o "verdadeiro" autor já faleceu e era um pederasta passivo.

Segundo Foucault, "a confissão é um ritual de discurso onde o sujeito que fala coincide com o sujeito do enunciado" (FOUCAULT, 1988, p. 61). O filósofo francês remete-se à 
confissão utilizada pela Igreja Católica em seus rituais como parte das penas que o fiel deve sofrer para se purificar e conseguir a absolvição de Deus. Tomo essa noção de confissão e me permito deslocar seu sentido, pois muito do que os médicos faziam com seus pacientes homossexuais se parecia com as sessões de confissão praticadas pela Igreja Católica. As experiências e métodos utilizados por Aldo Sinisgali, Leonídio Ribeiro, Edmur de Aguiar Whitaker e do próprio Jorge Jaime, demonstram que suas entrevistas com homossexuais não eram muito diferentes das confissões feitas pelos métodos utilizados pelos padres. Nas entrevistas, os homossexuais eram levados a narrar suas vidas com todos os detalhes aos médicos e estudantes de criminologia. (GREEN, 2000; FIGARI, 2007). Mesmo que não seja uma confissão forçada, conforme retrata Foucault, o diário é um modo de confissão. Representa uma instância em que o narrado e o vivido se juntam, se misturam e perdem a noção de limite entre o verdadeiro e o falso, o fora e o dentro da vida.

Para Philippe Lejeune,

diário é um espaço onde o eu escapa momentaneamente à pressão social, se refugia protegido em uma bolha onde pode se abrir sem risco, antes de voltar, mais leve, ao mundo real. [...] É fascinante transformar-se em palavras e frases e inverter a relação que se tem 
com a vida ao se auto-engendrar. Um caderno no qual contamos [...] é uma espécie de corpo simbólico que, ao contrário do corpo real, sobreviverá. (LEJEUNE, 2008, p. 262-264)

Sendo esse espaço no qual o sujeito se desnuda, o diário é também o lugar de se entregar por inteiro, confessar os desejos proibidos, os gostos considerados degradantes, a vida que pode ser inventada, vivida e revivida. Em se tratando dos sujeitos ditos perversos é um espaço de produção de prazer e, se lido por outros olhos que não os do sujeito ou de seus pares em prazeres, espaço de crítica, de assombro por parte de olhos científicos.

Foucault indica a mudança de um modo de produção e de interesse nas histórias contadas no ocidente devido ao desejo de se conhecer o outro para melhor controlá-lo. Segundo Foucault, adviria daí uma

metamorfose na literatura: de um prazer de contar e ouvir, dantes centrado na narrativa heróica ou maravilhosa das "provas" de bravura ou de santidade, passou-se a uma literatura ordenada em função da tarefa infinita de buscar, no fundo de si mesmo, entre as palavras, uma verdade que a própria forma da confissão acena como sendo o inacessível. (FOUCAULT, 1988, p. 59)

No diário, tornado literatura, de Lady Hamilton o eu que 
fala abre-se para o mundo para que se possa legislar, ou melhor, intensificar o discurso sobre os anormais e controlar o homem perverso: “[...] a conduta sexual da população é tomada, ao mesmo tempo, como objeto de análise e alvo de intervenção;" para que "[...] o Estado saiba o que se passa com o sexo dos cidadãos e o uso que dele fazem [...]" (FOUCAULT, 1988, p. 29). Lembro, mais uma vez, as palavras do "pederasta passivo", autor do diário de Paulo, de que seu texto foi feito com base na vida dos homossexuais famosos do Rio de Janeiro e que "sua alma" estava dentro da novela, o que corrobora a ideia de autoengendramento levantada por Philippe Lejeune. Essa vida inventada a partir da vida de vários homossexuais explicaria o interesse sobre a vida do outro, sobre a sexualidade do outro, que faz com que o autor da tese e quem publica a novela, homem de ciência, se interesse por essa confissão contida no diário para melhor esclarecer seus pares sobre o que fazer com esses perversos.

Paulo, o personagem da narrativa, é um sujeito em luta constante com sua sexualidade, que não se conforma em ser homoeroticamente orientado e tem várias de suas aventuras com medo de ser pego em flagrante. Ele é um arquétipo do homossexual culpado que quer viver conforme as regras da sociedade heteronormativizada e se encaixa na descrição 
que Jurandir Freire Costa apresenta:

Na distância intransponível entre o ideal sexual da maioria e a efetiva condição homossexual da minoria instalam-se a aflição, a ansiedade, o ressentimento e o sentimento de vida abortada, o que leva os sujeitos às mais extravagantes posições subjetivas na vida amorosa. (COSTA, 1992, p. 97)

Paulo apresenta essa sensação de vida não funcional, pois ele não se encaixa nas expectativas que seu pai, e, por contiguidade, a sociedade traçou para ele. Não consegue se apaixonar pelas moças que Ihe são apresentadas e só tem olhos para os homens. Ele até tenta ter relações sexuais com mulheres, mas não consegue. A partir do sentimento de não corresponder às expectativas do pai ele se engendra como um sujeito ruim, baixo e sórdido. A novela se apresenta através da leitura, do próprio personagem, de seu diário, no qual narra o fim de uma relação sexual com um homem mais velho em 5 de março de um ano indefinido:

Ele ainda me enlaça a cintura desnuda e me beija as faces afogueadas... "Não, não chega... (sic) - imploro. Minha voz estruge cansada: é uma voz arrastada e cavernosa, voz de velho. "Que vergonha, meu Deus! Que vergonha! Ah! Enojamme minha fraqueza e o ridículo da minha situação. // Cambaleante vistome de novo, apressado, com medo da 
minha própria sombra. Como criminosos deixamos a escuridão dos bosques e ganhamos a estrada deserta. No alto do céu a lua brilha com mais intenso brilho. Um bonde longínquo faz-se ouvir numa curva do caminho. Calados, um ao lado do outro esperamos. "Você gostou?" pergunta-me. Como é devasso, como agora eu o detesto! Tomamos lugar no carro da frente que a essas horas tardias vem completamente vazio. "Você sabe que não há garotinho mais belo que você? Em que dia nos encontraremos de novo, hein, rapaz bonito?" Ah! Sou belo! Para que me serve essa beleza se é hedionda e anormal, se é uma beleza viciada e doente? (JAIME, 1953, p. 89)

O trecho acima demonstra como o personagem se vê e se reconhece. Sua situação é marcada pela vida escusa e por relações que ocorrem em lugares suspeitos devido ao fato de o sujeito homoeroticamente orientado não ter lugar na sociedade. Seu contato com o outro, seu semelhante, só pode ocorrer em locais escusos, no caso em um bosque, em um lugar mais afastado da cidade e sua relação é com um homem mais velho, que, mesmo demonstrando sentir atração pelo rapaz, deve ser desprezado, pois é indigno. Nesse sentido, conforme afirma Costa, ao tratar das relações dos homossexuais e suas concepções de mundo, tudo

que parece sublime ou edificante na boca de um homem ou de uma mulher, ao se 
dirigiremumaooutronasituaçãoamorosa, soa grotesco, ridículo e "aviadado" na boca de um homossexual. Na tradição do preconceito, homossexualismo é perversão, e perversão é parente próximo da animalidade. (COSTA, 1992, p. 93-94)

Para o narrador do diário, que enxerga-se como dotado de uma beleza hedionda, viciada e doente, a fala de seu parceiro lhe soa sórdida, torpe. Seu parceiro é um "devasso", detestável, que, assim como ele, age como criminoso. Notese que o próprio Paulo, naquele momento da narrativa do diário é um jovem, conforme se pode depreender da fala de seu parceiro. No entanto ele reconhece sua voz como de um velho, pois se percebe como um sujeito gasto pelo tempo devido à sua conduta sexual. É com essa concepção negativa de si mesmo que o personagem fará a confissão de suas relações sexuais em seu diário.

Para Foucault,

a confissão se abre, senão a outros domínios, pelo menos a novas maneiras de percorrer tais domínios. Não se trata somente de dizer o que foi feito - o ato sexual - e como; mas de reconstituir nele e a seu redor, os pensamentos e as obsessões que o acompanham, as imagens, os desejos, as modulações e a qualidade do prazer que o contém. (FOUCAULT, 1988, p. 62-63) 
Isso é perfeitamente representado na releitura do diário que o personagem Paulo afirma fazer. Os relatos de atos sexuais são apresentados da seguinte forma: Em 15 de novembro Paulo vai à casa de um rapaz no Jardim América: "Ficamos semi-despidos. E fui por ele sofregamente amado. Aos poucos torno-me um pederasta" (JAIME, 1953, p. 90). Em 22 de janeiro ele está envolvido com Luís, rapaz recémchegado do Sul. Em um passeio em seu barco, Paulo revela a seu diário:

Roçaguei minhas carnes nas dele. No banheiro fi-lo enlaçar-me a cintura. Sorriu para mim. Deixei-o me morder, resfolegar em cima de mim. No dia seguinte fomos a Santos. Amamo-nos novamente. (JAIME, 1953, p. 90)

Em 28 de janeiro, Paulo vai com um amigo a Santos e se envolve com um homem mais velho, que o convida a ir aos penhascos onde havia uma caverna deserta: "Tirou a roupa. Fez uma pose feminil e reclinou-se sobre as pedras limosas. Perguntou-me se eu era muito criança. Quis que eu ficasse nu também: chupou-me o pênis. Gozei. Trouxe-me de volta" (JAIME, 1953, p. 90). Em 10 de fevereiro, envolvese com outro homem e vai para o palacete deste que fica escondido entre as árvores. Mesmo com todo medo de ser descoberto, a relação ocorre: 
Nossas línguas se tocam de leve. Suas mãos irriquietas (sic) me afagam as costas nuas. "Eu te amo, eu te amo" - eu balbucio, ele balbucia. O mundo para mim num instante parece, (sic) desamparado, rolar aos meus pés. Vertigem deliciosa arrebata cada fibra dos meus músculos trepidantes. Deliro. Já não sei mais o que faço. Sou todo volúpias e inebriantes gozos. Entre seus braços hercúleos, sufocado por suas carícias felinas eu me sinto mulher, embora sendo homem, eu me sinto desfalecer fragilmente com a impetuosidade de suas carícias felinas. (JAIME, 1953, p. 91)

Desse modo percebe-se que a narração faz questão de apresentar as relações sexuais, muitas vezes com detalhes sutis, pois, se a palavra não diz tudo ela apresenta o que está no entorno da relação sexual. As descrições vão desde a culpa e o medo às posições que os sujeitos ocupam ou devem ocupar nessas relações. A postura do dono do diário é sempre muito feminina, o que pode indicar sua performance "passiva" diante do outro. Mesmo quando recebe uma felação de um sujeito mais velho que antes do ato apresenta uma pose "feminil", Paulo mostra-se passivo, o que fica explicitado pelo fato de o outro tê-lo trazido de volta dos penhascos. Este é quase sempre mais velho, mais forte, com braços hercúleos, quase sempre anônimo, com gestos felinos, como o último caso citado, a lembrar a inferioridade e a submissão de Paulo diante do outro. 
Ao mesmo tempo em que descreve suas ações de passividade não deixa de ser interessante como os beijos e o gozo são apresentados. O personagem abisma-se, delira em "inebriantes gozos" em uma "vertigem deliciosa". Esse vocabulário apresenta-se e pode ser lido como um contradiscurso, pois há prazer nas relações sexuais também. Nesses pontos, onde o personagem narra seu prazer nas relações sexuais, o texto parece ganhar uma nova vida, um desvio em sua função pedagógica, ou melhor, a pedagogia serve a outro amo que não a heteronormatividade e sua ordenação.

Com as confissões de Paulo, o leitor chega àquilo que Foucault nomeia como o inacessível das confissões. Os leitores foram apresentados ao que eles temem, mas ao mesmo tempo os fascina. O diário de Paulo é um espaço de representação daquilo que não pode ser tolerado em nossa sociedade, segundo o discurso heteronormativo. A literatura tomada como espelho por Jorge Jaime apresenta o personagem a ser combatido: o "doente tarado", aquele que vive na sordidez. No entanto seu diário deve ser olhado e estudado pela ciência.

Em um determinado momento do diário há a descrição de uma orgia da qual o personagem Paulo participa: 
Quando o álcool aquecia os ânimos tinha início o original espetáculo. Uns dançavam como bailarinas clássicas, davam gritinhos assustados, enquanto outros os beijavam, sôfregos de paixão, tontos de desejos. As luzes, pouco a pouco, desapareciam. Os convidados ficavam completamente nus. Seus corpos suados brilhavam na penumbra cinzenta que os envolvia. Os suspiros de prazer, como gemidos de moribundos, ecoavam por todos os aposentos. Jogavam-se no chão; uns bebiam a saliva dos outros. Que porcaria, meu Deus, que loucura irracional, que excitação interminável! Eu me entregava a todos. Eram saudáveis, altos, vermelhos, morenos, louros, eu queria todos, todos para mim. Gostava de sentir-me Cleópatra, rodeada por seus súditos. (JAIME, 1953, p. 96)

Nota-se o quanto a descrição vem carregada de juízos de valor por parte do narrador e da lei da cultura internalizada causando todos os desgastes possíveis ao personagem. A festa regada a álcool, as poses e as performances dos gays, gritos, beijos; a comparação dos suspiros de prazer como gemidos de moribundos. Essa relação antitética que transforma o que é prazeroso em algo hediondo e mortal está no cerne do discurso que Jorge Jaime quer trazer para seu livro. O exemplo que não deve ser seguido pelos homens de bem ao contemplarem o diário contendo a confissão do perverso. 
No entanto o narrador, o pederasta passivo, mesmo indignado com sua condição continua a narrar e as experiências dele se sucedem, reiteram-se, explicitam-se. Parte da estratégia do autor, o "Doutor" em Direito, em deslocar o ensino, o pedagógico a partir da narrativa do exemplo, se voltam contra seu próprio discurso. Note-se que ao mesmo tempo em que se horroriza com a orgia, o personagem descreve e gosta: "que excitação interminável" convive com "loucura irracional". O narrador afirma querer todos os homens à sua volta, o que não deixa de alimentar o imaginário do leitor. Como as informações não são de todo explicitadas elas permitem que os leitores busquem marcas de deleite e de modos de vida, uma espécie de receita, de como fazer as coisas, que, mesmo condenadas, fascinam. Há a reconstituição do prazer, a reiteração do ato como modo de se penitenciar, mas também como modo de demonstrar como ocorre o prazer.

O que distingue a literatura da realidade é o seu lugar de representação, transfiguração, mas ao representar, algo do real se imiscui nessa fiç̧ão assim como esta se imbui da realidade. Quando se vê sujeitos homoeroticamente orientados e suas práticas representadas não se pode perder de vista que o mesmo discurso utilizado para repreender, 
reprimir, isolar e estigmatizar também é capaz de facilitar, suplementar o sujeito de modo a que seu imaginário, seu desejo, seu excesso e sua falta se encaminhem para outro lado. Desse modo, o que foi utilizado para reprimir deve ser relido de modo a ser utilizado não só como experiência no modo de fazer, mas para se alterar o modo de pensar, inscrevendo novas práticas de discurso naquilo que já está estabelecido. A traição do discurso perpetrada inconscientemente e "quase sem querer" demonstra que o discurso da literatura é capaz de desvestir até mesmo os preconceitos mais arraigados e assim fazer com que o leitor que se quer mais ativo, mais presente no mundo, mais crítico com relação à vida, assuma o que lhe foi negado, deixe o recalque vir à tona e se possua como dono e senhor do seu destino.

Ao discurso heteronormativo deve ser dada a leitura de seu avesso, de suas regras e mandamentos como algo a ser desrespeitado e rasurado. Portanto, o texto de Jorge Jaime não deve ser visto como mera gozação ou relegado ao conjunto das banalidades, mas como importante instrumento de se repensar a cultura e seu modo de operar. Tirar a opacidade de sua escrita, liberando-a em seus mais diferentes aspectos inconscientes e reprimidos, demonstra que a literatura sempre se recusa a ser mero 
espelho da sociedade e pode contribuir para que se possa conhecer o imaginário de uma cultura e alterá-lo. Não se quer aqui julgar a qualidade do texto apresentado por Jorge Jaime, visto que a noção de estética emaranhou-se no gosto burguês e, portanto por demais entrincheirado nas noções heteronormativas; este artigo se propôs a analisar uma novela a partir daquilo que à primeira vista não é seu interesse, pois em seu texto pedagógico buscamos seu contradiscurso. Essa estratégia explicita que textos como esse são produzidos e vendidos como produtos científicos que pretendem estudar e sanar com simplificações questões complexas como o homoerotismo e seus diversos modos de desejar. Desse modo, ler o contradiscurso contido em Lady Hamilton é um modo de resistir à heteronormatização, bem como um modo de demonstrar como a literatura ultrapassa a mera manipulação que o discurso pedagógico pretende.

\section{REFERÊNCIAS}

COSTA, Jurandir Freire. A inocência e o vício. Rio de Janeiro: RelumeDumará, 1992.

FIGARI, Carlos.@s outr@s cariocas. Belo Horizonte: UFMG; Rio de Janeiro: IUPERJ, 2007.

FOUCAULT, Michel. História da sexualidade. A vontade de saber. (Vol. I). 16ed. Trad. Maria Thereza Costa Albuquerque e J. A. Guilhon Albuquerque. Rio de Janeiro: Graal, 1988.

GREEN, James N. Além do carnaval. Trad. Cristina Fino e Cássia Arantes 
Leite. São Paulo: UNESP, 2000.

JAIME, Jorge. Homossexualismo masculino. 2ed. Rio de Janeiro: editora O constructor, 1953.

LEJEUNE, Philippe. O pacto autobiográfico. Trad. Jovita Maria Genheim Noronha e Maria Inês Coimbra Guedes. Belo Horizonte: UFMG, 2008.

TREVISAN, João Silvério. Devassos no paraíso. 5ed. Rio de Janeiro: Record, 2002.

Fábio Figueiredo Camargo é Professor adjunto do ILEEL da Universidade Federal de Uberlândia (UFU). Possui Mestrado em literatura brasileira pela UFMG e Doutorado em Literaturas de língua portuguesa pela PUC Minas. É autor de A escrita dissimulada (Sografe, 2005) e um dos organizadores de Inventário do corpo - Recortes e rasuras (Veredas e Cenários, 2011).E-mail do autor: fabiocamargo@ileel.ufu.br 